\title{
O Laboratório Imaginário: práticas especulativas localizadas ${ }^{1}$
}

Jussi Parikka²

Tradução: Leonardo Souza ${ }^{3}$

Thawan Dias ${ }^{4}$

\footnotetext{
${ }^{1}$ Consideramos que, no contexto da versão em português do texto, o termo In Situ encontra melhor tradução na palavra "localizado". Quanto a expressão original Lab Imaginary, consideramos que ela pode também se referir aos imaginários acerca dos laboratórios. Então, conforme o exercício de apresentação de tais imaginários pontuado neste texto, optamos por traduzir o título do texto pela expressão 0 Laboratório Imaginário.

* Tradução realizada no âmbito do projeto de pesquisa e extensão do Laboratório Multicênico - Centro de Formação em Artes da Universidade Federal do Sul da Bahia (UFSB).

${ }^{2}$ Dr. Jussi Parikka é pesquisador da Teoria das Mídias e Professor na Universidade de Southampton. Seus livros e artigos analizam a cultura digital em rede e audiovisual. Parikka publicou extensivamente sobre a Arqueologia da Mídia, incluindo seu importante livro What is Media Archaeology? e também A Geology of Media, entre tantas outras importantes publicações sobre o tema. Parikka é um dos diretores fundadores do grupo de pesquisa Archaeologies of Media and Technology (AMT), sendo um dos organizadores da publicação que marca o trigésimo aniversário da Transmediale, lançado com o título Across and Beyond - Postdigital Practices, Concepts, and Institutions.

${ }^{3}$ Professor adjunto na Universidade Federal do Sul da Bahia, doutor em Poéticas Tecnológicas (EBAUFMG), mestre em Arte \& Tecnologia da Imagem (EBA-UFMG), bacharel em Ciência da Computação (DCC-UFMG), com formação em Artes Cênicas, Cinema e com Licenciatura em Artes. Na sua experiência docente, lecionou e coordenou cursos na Kabum, onde foi professor-fundador da primeira escola de Arte e Tecnologia de Belo Horizonte e também foi coordenador técnico do Laboratório de Artes Digitais 1 maginário da EBA UFMG.

Email: quilombo@gmail.com

${ }^{4}$ Bacharel em Arte, especialista em Arte e ex-bolsista do projeto que abrigou as atividades de pesquisa e tradução deste artigo.

Email: thawmsnpessoal@gmail.com
} 


\section{Resumo}

O presente texto apresenta uma tradução do capítulo publicado por Jussi Parikka, no livro Across and Beyond, de 2017, cujo título original é The Lab Imaginary: Speculative Practices in Situ. A publicação surge do projeto de pesquisa What Is a Media Lab, que Jussi Parikka desenvolve em conjunto com Lori Emerson e Darren Wershler. Trata-se de um importante texto para as reflexões acerca dos laboratórios experimentais das mídias.

Palavras-chave Arte e Tecnologia; Midia Lab; Hack Lab; Fab Lab; Design.

\section{Abstract}

What is a media lab? For that matter-what is a library? What is an archive? What is an experiment? These questions spurred Jussi Parikka to begin an ongoing research project in collaboration with Lori Emerson and Darren Wershler, and have led them and their collaborators into wide-ranging territories. In this essay from the recently published book across \& beyond, Parikka reports back from the lab and library-from MIT to Agbogbloshie, from the art exhibition to the startup incubator, to imagine the past and the future of the media lab.

Keywords Art and Technology; Media Lab; Hack Lab; Fab Lab; Design. 
Se o imaginário não existisse alguém teria que inventá-lo. De várias formas nós já o fizemos, pois o imaginário, como o concebemos, funciona como um tipo de dispositivo de produção de realidade que é irredutível a métodos psicológicos ou sociológicos de explicação. Em contraste a essas formas de explicação, o imaginário pode se tornar uma entidade muito mais interessante quando considerado como uma técnica com várias histórias e diferentes situações institucionais. Em outras palavras, o imaginário é ensaiado e praticado, bem como é institucionalizado, em vários lugares, desde bibliotecas até laboratórios. Essa ideia é propagada pelo argumento de Michel Foucault, com o qual ele afirma que:

O imaginário não é formado em oposição à realidade como se fosse sua negativa ou uma compensação. $O$ imaginário nasce entre signos, de livro em livro, no intervalo entre repetições e comentários. Ele nasce e ganha forma entre os livros. É o fenômeno da biblioteca. (FOUCAULT, 1998: 106)

Foucault, ao discutir Gustave Flaubert, relaciona o imaginário a uma técnica mediática específica: a da fabulação por meio de palavras escritas. Trata-se de uma serialidade de signos que ressoa em como Foucault delineia um projeto de arqueologias de conhecimento, as quais são entendidas como o estabelecimento de discurso sobre $o$ que pode ser conhecido e percebido, ainda que não seja aceito como realidade. $\mathrm{Na}$ biblioteca, todo um mundo imaginário pode emergir. Durante um período, a leitura foi percebida com tamanho perigo para as mulheres, que a ambição do sonho bovarístico ${ }^{5}$ foi patologizada como uma doença mental. Que outros tipos doenças (atribuídas ao gênero) emergem como parte dos imaginários ligados a uma biblioteca? Que outros tipos de experiências limítrofes emergem a partir de práticas midiáticas que ganham espaço nos limites daquilo que é aceito como parte da realidade ${ }^{6} \mathrm{e}$ o que pode advir do imaginário? A lista pode ser longa, para além da leitura e escrita, ela inclui outros tipos de fabulação sobre o mundo: o que é real, o que não é real e vários espaços e tempos que podem também ser alcançados para além da interface planejada para o objeto livro e para o espaço da biblioteca ${ }^{7}$.

\footnotetext{
${ }^{5} \mathrm{O}$ sonho bovarístico se refere a uma modalidade de comportamento comumente indicado pela expressão "sonhar acordado", através da qual uma pessoa crê em si como protagonista de um romance, apesar das adversidades cotidianas.

6 Tratamos aqui o termo do original "Actual" como aquilo que é aceito como parte da realidade, apesar de guardar suas estranhezas.

7 Do original: "times and spaces that can also be reached outside the design interfaces of the book and the library".
} 
Geralmente, os imaginários estão deslocados. Eles são projetados pra mudar o espaço do possível. A biblioteca e o museu, de diversas formas distintas, situam espacialmente o imaginário, mas outras instituições têm feito o mesmo em relação a este deslocamento, que é espacial, formal e temporal. Tais deslocamentos correspondem à narrativa teórica que discute sobre o caráter emergente da mídia técnica:

Uma vez que memórias e sonhos, os fantasmas e os mortos, se tornam tecnicamente reprodutíveis, leitores e escritores não necessitam mais dos poderes de alucinação. Nosso reino dos mortos foi retirado dos livros nos quais eles residiram por tanto tempo. (KITTLER, 1999: 10)

O estúdio é um outro tipo de espaço óbvio para o imaginário, mas, em relação à cultura midiática tecnológica, vou focar em um outro espaço que tem ganhado relevância na arte e no design nos últimos anos: o Laboratório. Demonstrarei como o Laboratório é um espaço que incorpora práticas que deslocam as coordenadas do que é possível. O $\mathrm{Lab}^{8}$ tem uma história cultural significativa, tanto como um espaço real, como também um espaço ficcional para pesquisa científica, e que tem se tornado muito mais do que anunciam as práticas atuais de experimentos e de produção de conhecimento. A mitologia do laboratório é, ela mesma, um tópico que escapa aos limiares de qualquer "história real" do que os laboratórios são. Acrescente a isso o fato de que, nos últimos anos, uma crescente quantidade de instituições de mídia e humanidades tem delineado a ela mesma como "Labs", laboratórios especializados em design, criatividade e, até mesmo, especializados em uma diversidade de trabalhos do imaginário ou, pelo menos, especializados em uma diversidade de arqueologias midiáticas de engenharias reversas de tecnologias e narrativas culturais sobre a tecnologia. Bureau D'estudes ${ }^{9}$ indica a existência de um planeta laboratorial, o qual se refere a laboratorialização do conhecimento, além de designar o complexo que envolve um circuito universitário, de entretenimento, bélico e científico originados nos séculos XX e XXI como a definição da situação planetária que instala infraestruturas de poder e tecnologia. Trata-se do mundo como laboratório, ou, pelo menos, essa é a forma como a retórica anunciada pelo Bureau D'estudes justifica as cidades inteligentes contemporâneas, instituições universitárias e HackLabs. ${ }^{10}$

\footnotetext{
${ }^{8}$ Ao longo de todo o texto, o autor se refere ao laboratório pela abreviação $L a b$.

$9 \mathrm{http}: / /$ laboratoryplanet.org/en/

10 O Bureau D'Etudes pontua sobre o planeta enquanto laboratório: “Desde a segunda grande guerra, o planeta está sendo gradualmente transformado em uma escala de um único laboratório. O modelo antigo de fábrica mundial cedeu espaço ao modelo de laboratório mundial. Objetos oriundos deste laboratório, podemos nós também sermos sujeitos? Podemos exigir algo desta enorme máquina que se tornou
} 
Nesse contexto, levanto a seguinte pergunta: Fora dos laboratórios, como espaço de fabulação e projeção de sonhos e, ao mesmo tempo, esse lugar que incorpora a forma escrita do imaginário, como vamos nos engajar em práticas de especulação em Mídia e Design, assumindo sua característica enquanto espaços contemporâneos lúdicos para a imaginação, para a prática tecnológica e ativismo ${ }^{11}$ Uma questão como essa é muito ampla pra ser resolvida em um breve artigo na medida em que ela toca nas tenções assumidas entre causalidade ${ }^{12}$, regularidade e resultados inesperados, experimentação e padronização, criatividade e rotina e diversos outros pólos opostos que formam os meios pelos quais as atividades artísticas e científicas são vistas como distintas. Ainda assim, tentando evitar esses estereótipos sobre conhecimento científico e práticas criativas, são necessários mapas críticos das práticas laboratoriais. Tais mapas críticos, genealogias e investigações são remanescentes das várias formas em que, no século XX, a laboratorização do experimento artístico e de design, bem como o interesse da prática pós-estúdio em espaços alternativos para a criação, têm oferecido formas de entender sobre como as instituições formais criam condições para o amplo campo da prática criativa.

A postura especulativa que se tornou parte da cena dos laboratórios de Design e Mídia tem comumente assumido um tom progressista orientado ao futuro ("Inventar o Futuro" é o termo utilizado pelo MIT Media $L A B$ desde a década de 80), mas estou interessado em outro tipo de horizonte temporal: inventar o passado, assim como inventar escalas temporais alternativas, ou inventar novas perspectivas temporais. Portanto, o laboratório passa a ser percebido como um lugar de experimentação, que possui temporalidades alternativas, de onde emerge uma política intrínseca do tempo na cultura pós-digital.

\section{II}

O laboratório institucionalizou-se como um lugar-chave para a invenção. Como Alfred N. Whitehead pontua no começo do século XX, não são somente as tecnologias

autônoma e está se desenvolvendo de acordo com sua própria dinâmica? Podemo nós redirecionar os caminhos e os objetivos deste laboratório?" Citado do site do Laboratory Planet: http://laboratoryplanet.org/en/.

$\frac{11}{11}$ Existem muitos exemplos relevantes, mas em termos de ativismo recente, onde a retórica do laboratório pode ser mobilizada tal como em uma rede feminista, o Deep Lab é um projeto que mapeia questões entre ativismo, arte, design, e cultura da Internet: http://topicalcream.info/editorial/deep-lab-2/ (acessado em 20 de setembro de 2016). Este também é um bom exemplo sobre como a noção de laboratório não está necessariamente contida por arranjos arquitetônicos normais, e se torna uma rede de participantes trabalhando em uma escala geográfica mais ampla e com um conjunto mais amplo de questões sociais globais.

12 Assumimos aqui a tradução de regularity outcome como a causalidade intrínseca a resultados regulares em experimentos científicos. 
isoladas, como a engrenagem, que definem a natureza avançada da modernidade, mas sim o método:

A maior invenção do século XIX, foi a criação do método de invenção. Um novo método surgiu na vida. A fim de compreender a nossa época, nós podemos negligenciar todos os detalhes das mudanças, como os viadutos, os rádios, o telégrafo, as máquinas de engrenagens, os corantes sintéticos. Nós devemos nos concentrar no método mesmo, essa é a verdadeira novidade que rompeu com as fundações da civilização antiga. (WHITEHEAD, 1925: 91)

Whitehead muda o foco sobre a ciência, passando a considerá-la algo semelhante a uma mina, em que faz-se uma investigação geológica, peneirando ideias que lidam mais do que somente com afirmações científicas e proposições lógicas, diferenciando-a, assim, da perspectiva em que a ciência é uma contemplação puramente cognitiva de novas ideias. Ademais, "um período intenso de design imaginativo" (WHITEHEAD, 1925: 92) é necessário para que ideias se transformem em produtos, Whitehead continua, soando mais como um pensador de Design de Prototipação do que como um filósofo da Técnica Moderna. Como parte da emergência das universidades de pesquisa e também de outros espaços de trabalho experimental, esse método acarreta na institucionalização de espaços específicos. Os laboratórios se tornaram padronizados como uma característica fundamental da ciência da Física e da Química, mas também da Engenharia: Os Laboratórios Menlo Park liderados por Thomas Edison foram muito debatidos como um lugar que conjugava investimento e engenharia criativa, enquanto o laboratório de Nikola Tesla se tornou uma espécie de paralelo daquele espaço mítico do criador solitário (um homem) de invenções tecnológicas. O método de invenção foi também a criação de um lugar de invenção, um espaço de invenção que ressoa nos espaços paralelos ao estúdio (como aqueles de atividades de criatividade artística) e também ressoa nos seminários e as bibliotecas (como os espaços das atividades de humanidades), mas com um conjunto distinto de herança experimental que o método de invenção carrega consigo.

Thomas Edison foi uma figura sintomática. Ele gerenciou tanto seu lado de figura idealizada - o gênio solitário -, mas também se permitiu estar ao lado de um coletivo de especialistas em instalações que o auxiliavam desde 1876. Mesmo antes do Menlo Park, Thomas Edison esteve extremamente consciente do que ele necessitaria para criar sua versão do que mais tarde seria chamado de Mídia Lab. Ele buscou por todo tipo de aparato elétrico e qualquer quantidade de químicos para experimentação, entretanto, certamente não foi o kit que ele tinha em mãos, ou o conjunto de 
experimentos, que definiu o surgimento, no século XX, do laboratório tecnológico, mas sim foram as novas formas de gestão dos espaços que definiram o surgimento de métodos que conjugaram ciência-engenharia-mídia em uma só realidade do século XX.

Bruno Latour tem escrito sobre o poder efetivo de um laboratório como um lugar de mudança de perspectiva. Essa mudança gradual no entendimento da ciência, como a prática situada em um espaço, em que o experimento é, ele mesmo, parte de uma variedade de considerações sociais, forma uma situação particular de tentativa e erro, contenção e distribuição. Como Latour delineia, o poder do laboratório reside nas suas possibilidades como um lugar de tentativa e erro, que reúne poderes especiais de lidar com a escala que vai desde a interface do Lab até o mundo externo.

Latour discute o papel do laboratório na fazenda de micróbio de Louis Pasteur no século XIX, e a suas massivas consequências sociais relacionadas às características locais, as quais dizem respeito sobre o controle das práticas de temporalidade e recursividade. De fato, a potência do laboratório reside em uma "construção especial de laboratórios de forma a reverter a escala do fenômeno, tornando os eventos passíveis de registro, e então, acelerando a frequência dos experimentos, possibilitando que muitos erros surjam e possam também ser registrados" (LATOUR, 1983: 165).

É claro que a discussão de Latour é específica para aquela prática científica particular na sua relevância para a saúde, a fazenda, os animais, mas indo até além, observando todo um conjunto de materiais e fatores narrativos que emergem. Mas, algumas de suas percepções facilitam pensar sobre uma variedade de outras práticas laboratoriais, desde os primeiros laboratórios de tecnologia e invenção até as versões mais recentes dos laboratórios de Mídia e Design. De fato, como Latour elabora, esta auto-contenção do laboratório é somente relativa. Para ele "outra razão do porquê essa relação dentro/fora é irrelevante se dá pois, neste exemplo, o laboratório se posiciona precisamente para reproduzir, dentro de seus muros, um evento que parece estar ocorrendo fora, e somente fora," (LATOUR, 1983: 154). o que enfatiza o laboratório como um deslocamento de escala de um conjunto de variáveis que são debatidas em outros níveis.

Os experimentos com materiais do século XIX e do início século XX já envolviam operações de reversão de escala, operações para trás e para frente. Não somente fatos foram descobertos ou produzidos, mas também toda uma variedade de produtos colaterais, incluindo, por exemplo, visões futurísticas que permearam o século XIX, bem como realidades parafisiológicas, as quais foram medidas em laboratório e atestadas com autoridade da assinatura dos especialistas. Um conjunto de novas coisas emergiu, se espalhou, e se tornou um extra, correlacionado ao produto da experimentação laboratorial. 
É seguro dizer que a institucionalização dos laboratórios (desde os laboratórios da Bell, até os laboratórios de design de Silicon Velley, passando pelas várias formas das instituições laboratoriais ligados ao MIT, chegando até o cenário do HackLabs da década de 80 e 90) se tornou crucial para o entendimento da expressão Inovação Midiática. O financiamento massivo de investimentos de toda sorte de laboratórios, principalmente nos Estados Unidos, ganhou paralelo com a retórica hiperbólica dos ganhos produzidos pelos produtos criados pelos laboratórios. Mas eles também produziram práticas de impacto material no campo cultural. Como John Beck e Ryan Bishop argumentam, a onda dos laboratórios de Arte e Tecnologia da década de 1960 foi caracterizada por um otimismo orientado ao futuro: "a Nova Fronteira, um mundo do futuro que deixa para trás os traumas do passado recente (a recessão, a Segunda Guerra Mundial) e traz à tona um olho que não cessa de observar o horizonte à frente". Como relembra Lori Emerson, no Media Lab do MIT isso já estava presente em seu mantra central "Inventando o Futuro", o qual foi a continuação de um tipo específico de perspectiva humanística, a de uma instituição de elite:

Esse ramo particular de humanismo sempre foi ligado, atado à perspectiva de um futuro imaginário. É um tipo particular de humanismo inumano que começou no grupo Arch Mach e veio a florescer na ideia do Midia Lab. É um tipo de humanismo que constantemente invoca um humano do futuro, imaginado, que não existe realmente, em parte porque integra uma noção de futuro cada vez mais ultrapassada e também porque esse humano imaginado para o futuro é sempre um homem, branco, privilegiado, altamente individualizado, descorporalizado, ocidental. (EMERSON, 2016)

Os imaginários são sempre levados em conta em uma teia de condições políticas e econômicas. Os discursos sobre a invenção do futuro como atividade laboratorial são expressões de interesses corporativos referindo-se a seus próprios mundos dos sonhos, impossíveis e extemporâneos. Portanto, como uma alternativa, quero recorrer um outro tipo de prática ligada ao espaço e ao imaginário, bem como outras arqueologias da mídia, como forma de oferecer, não só projetos críticos e engenharias reversas, mas como forma de impulsionar a mudança de perspectiva, o efeito escalar, do laboratório como a reinvenção do tempo, projetando um tipo diferente de futuro que se orienta também pelo passado. A invenção de uma tecnologia, seja ela nova ou existente, é sempre uma invenção de uma temporalidade particular. 
III

Como prototipar o passado? Essa foi a pergunta que guiou o Maker Lab na área de Humanidades da Universidade de Victória. Liderado por Jentery Sayers, este laboratório está profundamente envolvido com o estilo de arqueologia da mídia que prevaleceu em várias publicações teóricas sobre mídia e em vários escritos alternativos sobre os laboratórios. Sayers e Tiffany Chan apresentam seus laboratórios como um lugar de metodologias de teoria das mídias e de design:

Tecnologias que não existem mais ou que funcionam como se não fossem necessárias. As tecnologias que prototipamos são datadas entre 1850 e 1950, as quais nos dão um senso de história da mídia anterior à computação pessoal, mas posterior ao controle de responsivo e à mecânica relacionada a ele. Estes protótipos geralmente informam a tecnologia dos dias de hoje, dando a ela um senso de textura e de mudança com, por exemplo, vestíveis, computação nas nuvens e reconhecimento ótico de caracteres. ${ }^{13}$

Como um tipo de projeto de especulação reversa, que foca no passado, essa abordagem entra em sintonia com a ideia de Garnet Hertz, a qual versa sobre o passado como uma loja de invenções. E ainda, está claro que não se trata de uma mídia para o imaginário no sentido completamente fabulado, mesmo se explicitamente tratasse sobre "ausências no registro histórico". A prática institucionalizada do laboratório continua o discurso do fabricante, na medida em que apresenta uma história baseada no experimento prático que seleciona tecnologias e técnicas de projetos já estabelecidos, ao mesmo tempo em que desenvolve outras novas tecnologias como os kits. Uma partechave dos projetos de metodologia dos laboratórios (ambos conceitual e relacionado a tecnologias de fabricação digital) são os "Kits para a História Cultural", explicados por uma abordagem humanística para a pesquisa:

No lugar de manter a comunicação da pesquisa em humanidades somente no formato escrito, esses kits de códigos aberto encorajam a experimentação prática que com frequência resiste divertidamente ao instrumentalismo e também ao determinismo. Ao fazer isso, esses kits incitam seu público a considerar a dimensão histórica da particularidade

\footnotetext{
${ }^{13}$ Darren Wershler, em entrevista com Jentery Sayers e Tiffany Chan cujo título da publicação foi "Prototyping the Past: The Maker Lab in the Humanities at the University of Victoria" Disponivel em http://whatisamedialab.com/2016/05/10/prototyping-the-past-the-maker-lab-in-the-humanities-attheuniversity-of-victoria/.
} 
material dos mecanismos, pontuando que eles estão embutidos na cultura, sem assumir que, no presente, nós podemos sempre experienciar o mundo tal como o faziam antes. ${ }^{14}$ (BELOJEVIC, 2014)

Este kit se torna, ambiguamente, um dispositivo conceitual e de suporte, mais do que um artefato. Ele está inserido em um tipo de versão acadêmica do FluxKit, remetendo aos projetos do grupo Fluxus. O Um Kit, o "Primeiro Kit de Tecnologia Vestível", é uma caixa de joias de madeira, que contém protótipos de vestíveis com eletrônicos móveis. Nesse tipo de kit, a história da mídia se torna tátil. Outra maneira de colocar isto seria dizer que o artefato, ou o produto, é, em si, uma espécie de dispositivo para problematizar o que é entendido como: passado "real"; e os possíveis imaginários em torno uma determinada tecnologia ou situação histórica. Neste caso, surge um tipo de disjunção temporal e ela trabalha para enriquecer o sentido de contemporâneo enquanto um conjunto de sobreposições de camadas temporais. Nese contexto, o kit está embutido em um mundo rico de considerações sobre as relações sociais e imaginários que estão compreendidas entre os passados e os potenciais presentes, oferecendo uma disjunção de relações temporais, as quais não devem ser pensadas apenas no sentido direcional passado-presente-futuro. Eis a resistência lúdica do kit um tema que ressoa com o que Geert Lovink tem chamado de "contra o grão", que produz uma interessante ruptura com epistemologias do tempo da mídia, aceitas muito facilmente como certas (LOVINK, 2004: 11). A potencialidade de lidar com o deslocamento espacial e temporal do laboratório torna-se uma ruptura, e a institucionalidade do laboratório se torna uma potência para uma forma diferente de "inventar o futuro".

Uma versão interessante de um laboratório foi desenvolvida no Signal Lab da Universidade de Humboldt. Berlim, que sedia aquele Lab, é rica em outras mídias locais históricas, tais como o projeto Atlas of Media Thinking e Media Acting, uma cartografia da teoria e prática da mídia. Para um laboratório, a especificidade do local é parte similar do apelo do Fundus e do Signal Lab, mas com um tipo de abordagem de máquina do tempo. O Fundus está fortemente ancorado no trabalho teórico de Wolfgang Ernst e é, ele mesmo, uma espécie de mistura de coleção, depósito e laboratório, com um forte imperativo de mãos à obra. O espaço-irmão, o Signal Lab, é um projeto relacionado que impulsiona o ensino da mídia para além dos textos da teoria da mídia a fim de "ensinar eletrônica, programação e tópicos da informática/computador/ciências do ponto de vista

${ }^{14} \mathrm{O}$ "kit" tem forte relação com alguns métodos em Design Crítico, como cenários, cultural probes, props.. Ver também DUNNER, Anthony. TALES, Hertzian. Electronic Products, Aesthetic Experience, and Critical Design. Cambridge, MA: MIT Press, 2005. 
da teoria das mídias", ${ }^{15}$ como pontua Stefan Höltgen. Isso se relaciona com a primazia do Sinal, o Sinal como o objeto de análise, ou o que Ernst enfatiza como o aspecto operacional da mídia: a mídia é primariamente mídia somente quando em operação, mas, quando em operação, funciona como dispositivo crítico de tempo.

As várias coleções de objetos não são tratadas como coleções no sentido arquivístico, elas são feitas para serem tocadas, investigadas, e não estão organizadas em uma ordem arquivística, mas sim como experimentos de laboratório com uma qualidade histórica associada a elas. A lista de objetos-esquisitices seria longa. Desde o familiar ${ }^{16}$ até o menos obviamente relacionado à mídia, tais como os instrumentos técnicos do Fundus, incluindo ali os osciloscópios e muitos outros dispositivos de medição. Focados em dados e técnicas emergentes, fazendo uma engenharia reversa nas funções de hardware, estes espaços invertem nosso sentido comum de "Humanidades Digitais". Os objetos associados a tais espaços são, então, aparelhos de laboratório que fabricam maneiras de pensar sobre o tempo: nem tanto histórias imaginárias, e sim, maneiras pelas quais técnicas específicas sustentam nossas noções de tempo.

Então, esses tipos de laboratórios se tornam estágios para a experimentação e observação do tempo e de sinais em uma perspectiva de tempo crítico. Apesar de serem tão abstratos como parecem, eles funcionam em termos bastantes concretos de análise. Ernst explica que "a essência da mídia técnica fica evidente apenas na implementação de suas operações" (ERNST, 2016: 205) ${ }^{17}$, que deve ser compreendida através de noções de tempo, as quais devem ser complexificadas posteriormente em situações de análise: "É, portanto, apropriado empregar conceitos que nem sempre já tenham proximidade técnica entre figuras temporais e um significado transcendental, sendo também apropriado carregar estes conceitos com um imaginário chamado história".

Em uma mudança curiosa sobre a presença das culturas de laboratório no passado ${ }^{18}$, elas são agora chamadas de arqueologia da mídia ou outros laboratórios de mídia alternativa que se envolvem com Mídia Zumbi ${ }^{19}$ ou projetos especulativos de culturas midiáticas passadas. Os objetos da novidade tecnológica do final do século XIX

\footnotetext{
15 Jussi Parikka realizou entrevista com Stefan Öltgen de onde coletou o trecho relacionado.

${ }^{16}$ Commodore 64 foi o principal artefato em um recente workshop/curso intensivo no Signal Laboratory.

${ }^{17}$ Ver também ERNST, Wolfgang. Sonic Time Machines. Amsterdam: Amsterdam University Press, 2016.

${ }^{18}$ Os quais eram os novos laboratórios de mídia há cerca de cem anos, incluindo Menlo Park e outros.

${ }^{19} \mathrm{Um}$ entendimento de mídia zumbi trata-a como "uma metodologia de arte que aborda o passado, mas que se expande em um conjunto mais amplo de questões relativas à mídia descartada (morta)" mas que "está preocupada não só com a mídia que está fora de uso, mas com aquela que ressurge em novos usos, contextos e adaptações". Ver: HERTZ, Garnet; PARIKKA, Jussi. "Mídia zumbi: desvio de circuito da arqueologia da mídia para um método de arte". Teccogs: Revista Digital de Tecnologias Cognitivas, TIDD | PUC-SP, São Paulo, n. 14, p. 93-113, jul-dez. 2016. Disponível em https://www4.pucsp.br/pos/tidd/teccogs/artigos/2016/edicao 14/teccogs14 artigo03.pdf.
} 
e início do século XX agora se tornam pontos de entrada para abordagens alternativas que, em parte, alimentam o charme e o exotismo da mídia antiga. Isso também se aplica ao filme. Laboratórios de filmes atuais, e outros coletivos artísticos de experimentação, são locais de compartilhamento de expertise técnica e de um senso de comunidade em torno do espírito de "o que ainda não morreu"20. Isto aplica-se também aos laboratórios fortemente técnicos remanescentes das raízes (foto) químicas das mídias técnicas modernas em suas práticas alternativas de laboratório. O Process Reversal Lab nos EUA é dedicado a ser uma iniciativa artística com fotoquímica que, por meio de um olhar focado em acervos culturais baseados em filmes antigos, abre uma agenda conceitual mais ampla sobre o que um laboratório tecno-químico pode ser no contexto do imaginário:

Em tempos de descontinuidade em estoques de filmes, de salas sem franquia e de laboratórios de filmes abandonados, a perspectiva de criação cinematográfica pode parecer intimidadora [...] bem como excitante, na medida em que a indústria cinematográfica entra em colapso ao nosso redor, estamos ficando com uma oportunidade única; uma chance de reinventar o meio de uma imagem que não fora nem intencional nem desejado por seus exploradores capitalistas; uma tal que explora novas formas de ver, novas formas de ouvir e novas formas de falar sobre filme. ${ }^{21}$

Dado o modelo de cultura computacional massiva em escala planetária, seria tentador olhar para esses exemplos como uma prova de que a febre pelo laboratório se dá como se fosse um impulso nostálgico para ressuscitar o que foi perdido e tornado irrelevante: um anexo ao conhecimento e a um tipo retrô de cultura do Faça-VocêMesmo, cercado de bastante coisa obsoleta. Mas, diria que também é um tipo muito mais interessante de prática, uma vez que lida com especulações do passado por meio do conhecimento técnico, criando intervenções na prática técnica de forma que tais intervenções não se reduzem apenas ao digital. Isso se torna parte da agenda do Lab, um tema que será abordado na próxima seção.

\footnotetext{
${ }^{20}$ Bons exemplos incluem o LaborBerlin film lab com seus "film ain't dead" bem como diversos outros da Europa, tais como Filmwerkplaats (Rotterdam, the Netherlands), Átomo 47 (Portugal), e o Filmkoop Wien (Austria). Ver DUQUE, Elena. Celluloid and Self-Sufficiency: Artist-Run Labs. CCCB Lab, Research and Innovation in the Cultural Sphere. Feb, 2016. Disponível em http://blogs.cccb.org/lab/en/article cel\%C2\%B7luloide-i-autosuficiencia-laboratoris-autogestionats-perartistes/.

${ }^{21}$ Ver o site Process Reversal Lab: http://processreversal.org/.
} 
IV

Qualquer discurso interessado em futuros especulativos, passados alternativos, futuros pretéritos, passados que já foram futuros e outros tipos de contribuições ao imaginário também pode ser confrontado com questões sobre os espaços e situações nas quais os imaginários podem se dar. Ao desenvolver tais posições teóricas e metodológicas, podemos até falar de teoria ligada ao espaço/local que poderia ser entendida como uma versão do apelo de Peter Galison, o qual argumenta sobre uma teoria que se afaste de pressupostos universalistas e do empirismo stricto sensu. Como Rosi Braidotti sugere, esse tipo de especificidade pode reunir em um trabalho acadêmico a característica de ser aberto, responsável e compartilhável.

O laboratório, então, é uma maneira de considerar a natureza situada, ligada a um espaço/local, de um projeto institucional. Um aspecto particularmente interessante é sobre como, em alguns dos exemplos discutidos, o lugar ligado ao laboratório se torna tanto um espaço de projetos práticos, de mãos à obra, como também um espaço de engenharia reversa, no qual se descobre como as coisas funcionam, e onde se amplia a ideia do imaginário como fabulação indo em direção a outros tipos de metodologias críticas próximas à arqueologia da mídia. Esse tipo de ampliação é uma maneira de intervir e inventar novas formas de lidar com o tempo, que contribuem para a teoria da mídia e também para os debates sobre o pós-digital, sendo, então, uma maneira particular de abordar o tempo cultural da mídia. É importante perguntar sobre "a antropologia política de novas formas institucionais" (NEILSON, 2006), reconhecendo, ao mesmo tempo, que uma análise das situações institucionais pode ir além daquilo que já foi experimentado. Este breve projeto especulativo é também algo que pode ser ampliado de forma a considerar outros tempos que nascem em situações de laboratórios críticos em arqueologia da mídia e em projetos midiáticos ${ }^{22}$. $\mathrm{E}$ isso também envolve 0 desenvolvimento de práticas críticas e tecnológicas que permitam a consideração dos modelos de tempo linear do passado-agora-futuro como insuficientes para entender o trabalho dos laboratórios.

Relevante no contexto deste texto, a política da temporalidade em discussões sobre o pós-digital tem sido pontuada por Geoff Cox. A noção do pós-digital é reconhecida como uma maneira de discutir a natureza assíncrona da cultura da mídia contemporânea, que força-nos a considerar marcadores temporais como inadequados, tais como "o novo" ou "o antigo". Entretanto, Cox sinaliza que noções como pós-digital funcionam também como "conceitos de periodização" que podem, na verdade,

\footnotetext{
22 Segundo o autor, exemplo importante a ser considerado, trata-se da mídia técnica do tempo crítico, analisada no Signal Lab e no Fundus, a qual preza pelas micro-temporalidades que formam um nível diferente de manipulação do eixo do tempo e que leva a um tipo diferente de percepção humana.
} 
atrapalhar alguns de seus potenciais críticos. Ele continua este raciocínio por meio de uma discussão sobre o contemporâneo como um conceito complementar que facilita $o$ desenvolvimento de formas temporais suficientemente complexas, que tecem diálogos entre práticas e teorias na arte contemporânea e a cultura midiática.

Além do desenvolvimento de insights discursivos para o eixo da Arte Contemporânea e da Mídia, devemos também considerar em quais espaços este desenvolvimento acontece. Neste texto, o laboratório é sugerido como uma tal situação em que, embora tenhamos que reconhecer que a variedade de laboratórios torna impossível fazer qualquer generalização, aquela do tipo "inventar o futuro", marca corporativa do MIT Media Lab, difere radicalmente dos laboratórios de pequena escala que poderiam ser chamados de Laboratórios de Humanidades com Vocação Regional ${ }^{23}$ da nossa época. Estes últimos também se diferenciam dos ecossistemas Makerlab/Hack-lab emergentes na África Ocidental, como exemplo, em Agbogbloshie, Gana, um dos centros de despejo de lixo eletrônico. A plataforma do Agbogbloshie Makerspace soa inicialmente como qualquer Fab-Lab, com seus objetivos de trabalho coletivo, senso de comunidade e orientados à prototipagem: "dar as mãos para prototipar ferramentas e cocriar uma plataforma híbrida, digital e física para reciclagem, fabricação, compartilhamento e comercialização". No entanto, a realidade material e de infraestrutura apresenta um ângulo diferente. O laboratório está posicionado em uma realidade material de coisas usadas de segunda ordem, que surge por necessidade mais do que por mero interesse teórico. Em termos de cultura eletrônica, ele é também um contexto geopolítico diferente - outro aspecto que sublinha a necessidade de se pensar, como ponto de discussão crucial, em uma política do tempo/espaço na cultura pósdigital. Podemos considerar esse distanciamento geográfico, longe de narrativas habituais de locais de invenção dos EUA e da Europa, como um ângulo alternativo para a geopolítica em questão. A partir do deslocamento dos laboratórios de pesquisa e desenvolvimento, deixando a perspectiva de inventar o futuro para seguir pela perspectiva dos atuais laboratórios que tentam reinventar o passado como forma de se engajar com o presente, a questão dos laboratórios se torna uma forma de possibilitar imaginários da mídia como práticas localizadas.

\section{Referências bibliográficas}

FOUCAULT, Michael. "Afterword to the Temptation of St. Anthony". in: FAUBION, D. Aesthetics, Method and Epistemology. New York: New Press, 1998.

\footnotetext{
${ }^{23} \mathrm{O}$ termo utilizado é Locavore.
} 
KITTLER,Friedrich. Gramophone, Film, Typewriter. Trad. Geoffrey Winthrop-Young e Michael Wutz. Stanford: Stanford University Press, 1999.

WHITEHEAD, Alfred North. Science and the Modern World. New York: New American Library, 1925.

LATOUR, Bruno. "Give Me a Laboratory and I Will Raise the World". In: KNORRCETINA, Karin. MULKAY, Michael. Science Observed: Perspectives on the Social Study of Science. London: Sage, 1983.

EMERSON,Lori. Selling the Future at the MIT Media Lab. Berlin: transmediale, 2016. ver http://whatisamedialab.com/2016/02/17/selling-the-future-at-the-mit-media-lab/.

BELOJEVIC, Nina. Kits for Cultural History, 2014. Disponível em: http://maker.uvic.ca/kch/\#sthash.zd1Z4n21.dpuf.

LOVINK, Geert. My First Recession: Critical Internet Cultures in Transition. Rotterdam: NaiPublishers, 2004.

ERNST, Wolfgang. Chronopoetics: The Temporal Being and Operativity of Technological Media. trad. Anthony Enns. Londres: Rowman \& Littlefield, 2016.

NEILSON, Brett, ROSSITER, Ned. Towards a Political Anthropology of New Institutional Forms. Ephemera 6, no. 4, 2006, p. 393-410.

\section{Referência da publicação do artigo original}

BISHOP, Rian. GANSING, Kristoffer. PARIKKA, Jussi. WILK, Elvia. Across \& beyond A transmediale Reader on Post-digital Practices, Concepts, and Institutions. Londres: Sternberg Press and transmediale ed, 2016. Disponível em: https://transmediale.de/content/the-lab-imaginary-speculative-practices-in-situ. Acesso em 07/07/2020. 